\begin{tabular}{lcl}
\hline Bentham OPEN & Open Medicine Journal \\
CrossMark & Content list available at: www.benthamopen.com/MEDJ/ \\
\hline
\end{tabular}

REVIEW ARTICLE

\title{
Wikipedia as Informal Self-Education for Clinical Decision-Making in Medical Practice
}

\author{
David Matheson $^{1, *}$ and Catherine Matheson-Monnet ${ }^{2}$ \\ ${ }^{I}$ Carnegie School of Education, Leeds Beckett University, Leeds, UK \\ ${ }^{2}$ Centre for Implementation Science, Faculty of Health Sciences, University of Southampton, Southampton, UK
}

Received: January 26, 2017

Revised: April 25, 2017

Accepted: July 04, 2017

\begin{abstract}
:
Background:

For almost any topic, a Wikipedia page will appear among the first ten items of a search online. Wikipedia is also a site whose quality and reliability has been called into question.
\end{abstract}

\section{Methods:}

In this paper, we aim to discuss medical practitioners' use of Wikipedia, what this consists of and what it might be. We consider the context and history of Wikipedia before discussing the relationship between Wikipedia and the medical profession. In so doing, we will consider Wikipedia as a means of informal self-education and the extent to which it might inform clinical decision-making. We compare with the existing literature results from our two small-scale empirical studies of Wikipedia and clinical decision-making.

\section{Results:}

Notwithstanding issues over quality and reliability, Wikipedia's rules on verifiability are such that its articles are very heavily referenced, and this is just as true of health-related articles. The Cochrane/Wikipedia Initiative in improving the quality and reliability of medical and health pages in Wikipedia is significant in increasing reliability. Our respondents largely concurred with the results from earlier studies on the use of Wikipedia by medical practitioners.

\section{Conclusion:}

Perhaps the very doubt over Wikipedia's accuracy is its greatest strength as a means of informal education of doctors. That medical and health articles on Wikipedia can be so fully referenced and still be doubted is arguably a good thing and one whose effects may be spread into other, more trusted, publications. Hence, one might envisage a future where no one source is taken automatically on trust.

Keywords: Wikipedia, Informal education, Continued professional development, Medical education.

\section{INTRODUCTION}

In the days before the Internet, the only sources of information available to doctors seeking information quickly were print and colleagues. Print would comprise textbooks and journals and involve not only the effort of locating the relevant text and then the relevant part of the text but also knowing where to look in the first place. Availability would depend on what was to hand. Then there were the issues around datedness: even with the latest edition, it was possible that what one was seeking was already out of date or that there was a divergence of opinion in the medical community and one's text or journal article was only reporting part of the issue. All this changed as the Internet developed. No

\footnotetext{
* Address correspondence to this author at the Carnegie School of Education, Leeds Beckett University, Leeds LS6 3QQ, United Kingdom; Tel: (+)441138124704; E-mail: d.matheson@leedsbeckett.ac.uk
} 
longer was it the case that back issues of journals had to be consulted physically, going along one's shelf or in the very heavy bound volumes often found in university and hospital libraries. Literature searches that previously might have taken weeks could now be done in seconds - although it could take considerable time to sift through the pages of hits to get the most relevant material, if one were so inclined.

Looking for information to aid a clinical decision is, in contrast to a literature review conducted for an essay, more likely to be a somewhat pressing affair and, this being so, it is human nature to follow the path of least resistance. It should come then as no surprise that medical practitioners seeking information on the Internet should look at the sites that come at or near the top of the first page of their search results. And at or near the top of any page of search results on almost any topic is Wikipedia.

The aim of this article is to discuss medical practitioners' use of Wikipedia, what this consists of and what it might be. We will do so by considering the context and history of Wikipedia before moving on to discuss the relationship between Wikipedia and the medical profession. In so doing, we will consider how Wikipedia is used in medicine as a means of informal self-education and how it is evolving.

\section{THE HISTORY AND CONTEXT OF WIKIPEDIA}

From its very first page in 1991 [1], the World Wide Web has grown at a phenomenal rate to now exceed 1 billion pages in use at any one time [2], covering just about the entire range of human experience and knowledge. In addition, there is an unknown number of additional pages: those not currently in use and those not findable by search engines the latter includes the infamous Silk Road but also many innocent pages, such as those on company intranets whose owners simply do not want the public to be able to access them without proper authorisation [3].

The explosive growth of the World Wide Web led very quickly to a plethora of websites devoted to healthcare, some very serious, some quite frivolous, some misleading and some even dangerous. It also led to the publication of online of academic journals and even entire textbooks, some open access, most behind pay walls. However, these sites were, for the most part, material originally created for print that was then uploaded to the internet.

Wikipedia is an example of the so-called 'Web 2.0', a 'read and write' web [4] as opposed to the 'read-only' web which originated from the work of Tim Berners-Lee [5]. Web 2.0 is conceived as a space where users contribute content which they upload and share with others. In contrast, Web 1.0 is much more of a static space in which users access content uploaded by providers, not by each other. In the present day, the two coexist.

Well-known examples of Web 2.0 include Snapchat, YouTube, Vimeo, Facebook, Instagram, Twitter, LinkedIn and Wikipedia. George et al. describe these as "powerful symbols of a new generation of online tools and applications that foster user-generated content, social interaction, and real-time collaboration" [6].

There are however significant differences between Wikipedia and these other websites. For example, while one's Facebook friends can share or comment on what one has posted, they cannot alter it. A video posted to YouTube or Vimeo might be downloaded, edited and reposted but it cannot be amended ad hoc. Wikipedia, on the other hand, is an example of a wiki, a type of website where users can edit. According to Laurents and Vickers, "Wikis use a relatively simple editing syntax and [maintain] a public record of all edits to facilitate collaboration between multiple contributors" [7]. A Facebook page can have multiple commentators but these do not contribute to the original entry; they merely add their thoughts and viewpoints. Of note, as Azzam et al. state, is that "all Wikipedia edits are saved in perpetuity" [8].

Brioschi tells us that the idea behind Wikipedia began with Richard Stallman, whom she terms "the prophet of free software", who wrote in 1999 that the World Wide Web had the potential to evolve into a universal encyclopaedia covering the entire range of knowledge [9]. Wikipedia takes this notion much further than that suggested by Stallman and represents not only the potential to cover the whole of human knowledge but, rather than involve only an élite in the writing and editing of articles, allow anyone who has access to the World Wide Web to write or edit any article on any subject. This is what O'Reilly terms a "radical experiment in trust" [10], trust which is open to abuse as demonstrated by the case of the UK journalist Johann Hari who worked for The Independent until resigning in disgrace in 2011. Aikenhead describes how using a false identity, Hari had maliciously amended the Wikipedia pages of journalists he disliked... [He] had also edited his own Wikipedia page, lavishly flattering his profile" [11]. However, Metcalf and Powell reassure us that "a Nature survey of Wikipedia articles concluded that such high profile incidents are an exception rather than the rule" [12]. 
The very idea of allowing anyone to edit an entry in Wikipedia is a radical departure from the previous practice of encyclopedia entries being written by persons held to be experts in the field in question, such as was established with the creation of the Encyclopédie edited by Diderot and d'Alembert in 18th century France [13]. This open editing led very quickly to distrust of Wikipedia, a distrust shown by those academics who demanded that students do not cite it as a source for their essay assessments $[14,15]$. As Burgos and Bot put it:

\begin{abstract}
Allowing anyone to edit a page accepts the possibility of misconceptions, ignorance, and vandalism. Pages are susceptible to bias or confrontation, adding and deleting differing opinions back and forth with no real addition to the article. Many dismiss Wikipedia as a credible source because of this, without looking further into it. Wikipedia attempts to remedy these potential problems by giving guidelines and thoughtful policies on article editing [16].
\end{abstract}

This is exemplified by the extensive guidance provided by Wikipedia on assessing the quality of sources [17]. The guidance includes ensuring that all material is attributable to reliable, published sources with all quotations and anything that is open to challenge being supported by inline citations [18]. This, of course, assumes that the citations do not unfairly decontextualize the material cited or employ false citations and a lot of trust is placed in the wisdom of the crowd to identify and correct errors and misrepresentations.

In 2007, O'Reilly described Wikipedia as being "already in the top 100 websites, and many think it will be in the top ten before long. This is a profound change in the dynamics of content creation!" [10]

A decade later, as anyone who does a search on the internet can testify, for virtually any topic, Wikipedia will appear on the first page of search results and very frequently as the first result (other than advertisements) on that first page. As Burgos et al. put it, "search engines often offer a Wikipedia page at the top of the list for a given search" [16]. This builds on Laurents' and Vickers' statement in 2009 that "if the first page of results of a general search engine lists ten Web sites, Wikipedia can be found among those results in more than 70\% of cases" [7]. In addition, according to Dunne et al., a 2008 study "showed that $68 \%$ of search engine users click a search result within the first page of results (the default for Google is 10 results per page), and are unlikely to go to the second page of results" [19].

Meanwhile, there is evidence that attitudes in academia towards Wikipedia are changing, where as Konieczny puts it, "Wikipedia has become one of the most often consulted reference works, used by nearly all students as well as most academics and educators" [20] while Soules shows how, over five years in four universities of the California State University System, there has been a move across all levels of faculty to a more favourable attitude towards Wikipedia [21].

\title{
3. INFORMATION TECHNOLOGY AND HEALTHCARE EDUCATION
}

Since the invention of writing, there have been medical and healthcare texts [22] and these have often assumed, or been ascribed, a level of authority that close scrutiny of their contents may not always have justified. How else to explain the adherence, often in the face of overwhelming evidence to the contrary, to outdated and incorrect texts? Or to outdated methods such as those proposed and practised by Galen who staunchly defended the bloodletting against all who expressed any doubts as to its efficacy [23]. Strict adherence to Galen's ideas led George Washington's doctors to bleed him of around $40 \%$ of his total blood volume during the man's final hours [24]. This was despite the objections to this practice made by Paracelsus more than two centuries earlier [25], the nascent scientific-like approach of Paracelsus being ignored in favour of the authority accorded to Galen.

Every advance in communications technology has been met with predictions of the demise of the teacher, at least for more advanced learning [26], that learners would employ the new technology, teach themselves and do without teachers [27]. However, the learners would not create the learning material but rather use what was deemed worthwhile by publishers and those who controlled the media and risk a sense of alienation and isolation as a consequence [28]. This rather limited view of auto-didacticism simply replaces the physical teacher with a text, by a television programme, by a computer programme, by a website or by a selection and collection of any of these. Web 2.0 brings the possibility of a vision of online education much more akin to that of Paolo Freire in that the roles of teacher and learner are interchangeable [29]. 


\section{MEDICAL EDUCATION AND THE WEB}

The growth of evidence-based medicine, defined by Sackett et al. as "integrating individual clinical expertise and the best external evidence" [30], requires an openness to clinical advances and a critical faculty sufficiently developed as to be able to evaluate both the patient's presentation and the published evidence. And, as Greenhalgh suggests, there is a need to see not just the story but the story within the story. That is, in the development of the differential diagnosis to use not only the clinical signs and symptoms, but also the patient's context [31]. The practice of medicine is therefore not purely scientific in the sense of the reproducibility one might find in a scientific experiment but rather it is a combination of scientific knowledge and its application and the art of interpreting both that knowledge and the context within which it appears. Put bluntly, the practice of medicine requires acknowledgement that the diagnosis and treatment of a patient is not a scientific experiment in which one has control of all initial conditions; it is a field trial where some aspects may diverge from theory and where there may be question over which theory applies in the first place. As William Osler is quoted as saying: "Variability is the law of life, and as no two faces are the same, so no two bodies are alike, and no two individuals react alike and behave alike under the abnormal conditions which we know as disease" [32]. Add into this frame not only the vast amount of knowledge in medicine, and the debates around practice and treatment but also the rapid increase in that knowledge which has been producing an ever-increasing number of journals and we see a world in which simply keeping up with a narrow specialism can be quite a challenge, never mind having to keep up with a wider specialism or with areas that abut onto one's specialism.

\section{WIKIPEDIA AND HEALTHCARE EDUCATION}

According to Ozdoba, In the academic community Wikipedia plays a strange role. It is comparable to popular newspapers: nobody will admit reading Bild in Germany or the Sun in Great Britain, so where do the print runs of millions of daily copies come from [33]?

Having compared peer-reviewed journal articles and Wikipedia entries for the 10 costliest medical conditions in the United States, Hasty et al. found that most of the entries in Wikipedia contained errors and advised that "Health care professionals, trainees, and patients should use caution when using Wikipedia to answer questions regarding patient care" [34]. This was a point picked up by diverse newspapers and other media and amplified and generalised to the entirety of the medical content of Wikipedia [35]. The reviewers in Hasty et al. were described as doctors in training and non-specialists. Hence, they may well have not noticed errors in the peer-reviewed articles, such errors being far from unknown. To put further context on the findings of Hasty et al. in 2014 Wikipedia in English contained around 25,000 articles on health-related topics [36] (by 2015, it had exceeded 29,000 [37]). In other words, not only did Hasty et al. take as valid without further evidence findings from trainees but they also extrapolated to an extent not at all justified by their study and consequently were subject to severe criticism as regards their methodology. In their rejoinder to Hasty et al., Chatterjee et al. stated that "This study should be viewed with skepticism, and ... the authors should make the underlying data available to all for review" [35]. In contrast, Haigh's (2012) exploratory study of the accuracy of 50 Wikipedia pages on health found that:

The quality of the evidence taken obtained from the 2500 plus references from over 50 Wikipedia pages was of sufficiently sound quality to suggest that, for health related entries, Wikipedia is appropriate for use by nursing students [38].

Herbart et al. sought to assess the extent to which medical students in Germany, Austria and Norway used Wikipedia in their studies, how these students judged the quality of entries and whether they ever found errors when comparing Wikipedia with their knowledge, the literature, their gut feeling or with nothing at all [39].

Asked if they have ever found inaccurate medical entries on Wikipedia, 1,324 (97\%) students affirmed this. Of those, $861(65 \%)$ students did not know how to revise articles while 199 (15\%) let the false information unaltered, despite knowing how to correct articles [39]. Herbart et al. students of assessed the quality of articles either with respect to prior knowledge or by comparing with textbooks / discussing with faculty and peers [39]. In other words, they did exactly as suggested by Wikipedia's own article on reliability: they used Wikipedia as a starting point, bearing in mind that it is a general reference work and one needs to check facts and be aware that mistakes and omissions can occur [40]. However, it is well-known that text books and peer-reviewed articles can be out of date before they are even published and therein lies both a strength and a weakness of Wikipedia: it can be updated swiftly [40], but this may be with errors at times. As is shown in Wakefield et al. 1998 article on an alleged causal link between MMR triple vaccine 
and autism [41], it is not unknown for a peer-reviewed article to present conclusions which are simply not supported by the evidence provided. Indeed, by reading article of Wakefield et al. one is left to wonder how it ever even got sent to referees and not rejected immediately by the editor of The Lancet as unsuitable for publication as it is methodologically flawed across many dimensions (e.g. sample size, interpretation of data, unwarranted extrapolation, sources of information of questionable accuracy and so on). This is without going into the details of Wakefield's financial interests which came to light in the investigations by Brian Deer [42 - 44] whose work resulted in the 2011 case before the General Medical Council at which Wakefield and one of his co-authors were struck off the UK Medical Register.

Despite admonitions from universities and elsewhere regarding the accuracy and reliability of Wikipedia, studies show that $50-70 \%$ of practising and $70 \%$ of junior physicians use it as a medical information source [39, 45]. It goes almost without saying that a major attraction of Wikipedia is the fact that one can find there material on just about anything and this is equally true in topics in healthcare. An exception however concerns drug dosages as mention of these is specifically discouraged in the Wikipedia style manual for drug articles as such information is rarely within the scope of a general encyclopaedia and corruption of this information could result in serious harm [40].

There have been attempts at specialised wikis such as Medpedia, which was designed and run by medical practitioners. According to its founder James Curran, "Medpedia was a great experiment begun in 2007. Unfortunately, it never reached the size to be self-sustaining, and it ceased operations in early 2013" [46]. Sites such as radiologywiki.org and WikiSurgery.com have also gone to the wall but ganfyd.org survives, styling itself as "the free medical knowledge base that anyone can read and any registered medical practitioner may edit" [47]. The restriction on editors may have its benefits but so does lack of such restriction. A comparison of some random items on Ganfyd and Wikipedia highlights some stark contrasts. For example, if one searches for non-alcoholic fatty liver disease, one finds on Ganfyd ${ }^{1}$ an account some 200 words long, complete with several typographical errors but only three references to academic sources. The Ganfyd entry contains only the definition of non-alcoholic fatty liver disease and the histological scoring [48]. In contrast, the Wikipedia entry is nearly 2,000 words long, has no typographical errors, contains 54 references to academic sources (including JAMA, The Lancet, and the New England Journal of Medicine), and covers not only the definition of non-alcoholic fatty liver disease but also its signs and symptoms, causes, pathophysiology, diagnosis, management, epidemiology and its incidence in children [48]. Clearly, the longer an entry one has, then the more scope there is for mistakes and errors to creep in but, as a starting point for furthering one's knowledge, the Wikipedia entry would seem very much more useful than its counterpart in Ganfyd.

\section{IMPROVING THE QUALITY OF MEDICAL ENTRIES IN WIKIPEDIA}

While Herbert et al. cautiously suggest that Wikipedia should not be viewed as being inappropriate for its use in medical education [39], there remains concern over the reliability of the entries. Writing in the BMJ in 2014, Lane Rasberry - a Wikipedian, i.e. an editor of Wikipedia - stated that:

While the Wikipedia community has continually worked to improve the quality of its health content since the project's founding in 2001, few of the encyclopedia articles meet the quality standards that healthcare providers would expect before recommending that patients consult it [49].

Rasberry, however, goes on to state that Cochrane has granted Wikipedians, on request, subscription-free access to the Cochrane Library [49 - 51]. Cochrane "is a global independent network of researchers, professionals, patients, carers, and people interested in health", produces very highly regarded systematic reviews and its "work is recognized as representing an international gold standard for high quality, trusted information" [52]. The Cochrane / Wikipedia Initiative.

Was started in 2014 [and] supports the inclusion of relevant evidence within all Wikipedia medical articles, as well as processes to help ensure that medical information included in Wikipedia is of the highest quality and as accurate as possible. Trusted, evidence-based research can help people to make informed decisions about their own health care [51]. 
A way forward from this would be for medical schools, rather than to eschew, spurn and denigrate Wikipedia as a source of medical and health information, to embrace it fully and to encourage their students not only to consult Wikipedia critically but also to amend and correct entries and to rewrite, discuss, critique, and improve them [40]. This has been the case in Dentistry in the University of Dundee in Scotland where, under the guidance of a recent dentistry graduate and with assistance from Cochrane, groups of dentistry students work on a voluntary basis to improve the quality of Wikipedia entries on oral health and hygiene [53]. Azzam et al. tell us that medical schools need to embrace Wikipedia. Asserting that "most medical students use Wikipedia as an information source, yet medical schools do not train students to improve Wikipedia or use it critically" [8], Azzam et al. created a credit-bearing course for final year medical students at the University of California in San Francisco in which the students had to work to improve healthrelated articles in Wikipedia. This engaged the students not only in the checking for accuracy but also in the major communication skills of editing other people's work and in presenting sometimes complex material in as accessible a manner as possible. ${ }^{2}$ This could be taken a stage further and doctors, instead of creating new wikis like Ganfyd, could collaboratively edit the Wikipedia articles on the topics that interest them. By reading Wikipedia "cautiously and amend[ing] it enthusiastically" [7], doctors would perhaps demonstrate enlightened self-interest as patients would have more chance of accessing accurate information online and of hence bringing fewer misplaced notions into the consultation with their doctor. The more accurate are the entries in Wikipedia then potentially the less time the clinician has to spend debunking myths and correcting misinformation.

Wikipedia has arguably a familiarity to the patient that a patient-decision aid is unlikely to share. In addition, accessing patient-decision aids such as those created by the UK's NHS requires registration before one can complete the process [54]. Wikipedia does not. In this way, progressing through the patient-decision aid can, as we can testify from personal experience, engender a feeling uncertainty and exposure. Wikipedia has no such sense of the dramatic and its very anonymity can be a bonus for the user, be they patient or healthcare provider. It is therefore perhaps incumbent on doctors and other healthcare providers to do what they can to ensure that the health-related entries on Wikipedia are as accurate as possible, even if this only entails correcting errors that they stumble across. One of the essences of crowdsourcing is that everyone in the crowd need do very little for the result to be highly significant. This can be just as true for health-related topics in Wikipedia. As Natarajan and Racherla put it:

If we invest time on this web resource today, [doctors] may in the future have a substantial amount of free constantly updated medical literature under a single umbrella [55].

Masukume et al. take this call further, by suggesting that medical journals actively promote and incentivise Wikipedia editing by the health-care community so that the most commonly used source of online health information is as reliable as possible [56].

With its 56 active editors and 36 inactive editors (deemed inactive when they have not contributed to editing for over a month) [50], WikiProjet Medicine goes some way towards the goal of improving reliability as it brings together interested parties and "aims to manage and help in curation of Wikipedia's medical articles" [50]. The discussion page of WIkiProject Medicine gives a good indication of what it is about, bringing together interested parties from both lay and professional spheres and debating, for example, appropriate sources for images, what counts as evidence and so on [57]. The home page shows the diverse projects and partnerships in which WIkiProject Medicine is involved, including the Cochrane / Wikipedia Initiative [51], and the Wikipedia education program in medicine [58] as well as the Wellcome Trust-funded post of part-time Wikipedian in residence at Cancer Research UK [59]. This last shows one of the weaknesses in the Wikipedia method of editing in that an out-of-date page can remain without update. In this case, it is a matter of amending tenses and nothing more. In the Wikipedia education program in medicine, students are given "an assignment which includes editing the Wikipedia article for any topic taught in the class" [58], an example of which is the class at UCSF [8] outlined above.

\section{USING WIKIPEDIA [OR NOT] TO AID CLINICAL DECISION-MAKING}

In 2009-10 we conducted a small scale opt-in survey of doctors' use of Wikipedia as an aid to clinical decisionmaking [110 responses across all grades] [60,61] and repeated the process in 2016 (164 responses across all grades) [62]. In both cases, a cacade method was employed, with respondents encouraged to pass on the questionnaire to their

\footnotetext{
${ }^{2}$ An example of the course can be found at https://en.wikipedia.org/wiki/Wikipedia:WikiProject_Medicine/UCSF_Elective_2013
} 
peers. The aim in both instances was not to get a representative sample but rather to get an indication of feelings towards the use of Wikipedia as an aid to clinical decision-making.

Given the media exposure of the likes of Hasty et al.'s rather strong extrapolation [34] and various media's further extrapolation of this [35], it is no great surprise that in 2016 a smaller proportion of respondents should agree that they have ever used Wikipedia for medical information than was the case in 2009-10 $(\mathrm{p}=.008)$.

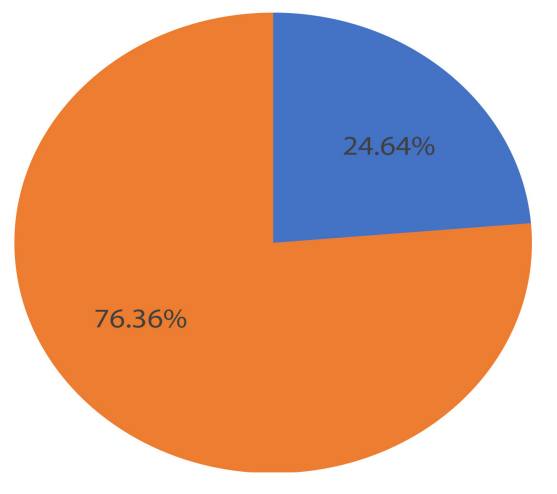

$2009-10(n=110)$

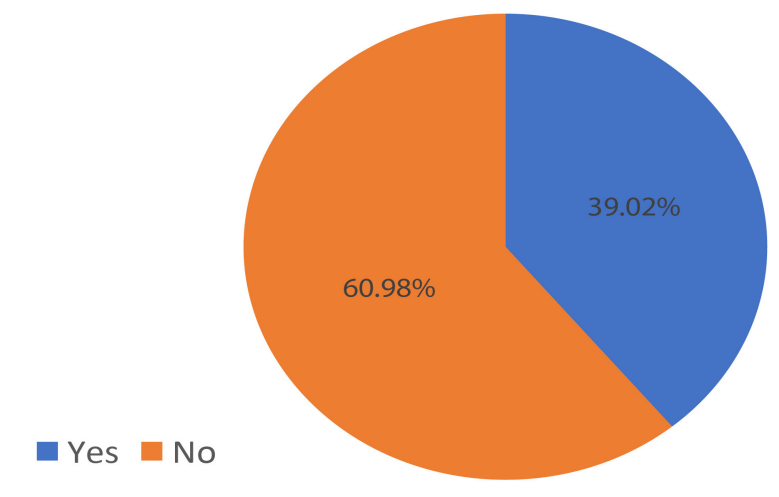

$2016(n=164)$

Fig. (1). Have you ever used Wikipedia for medical information?

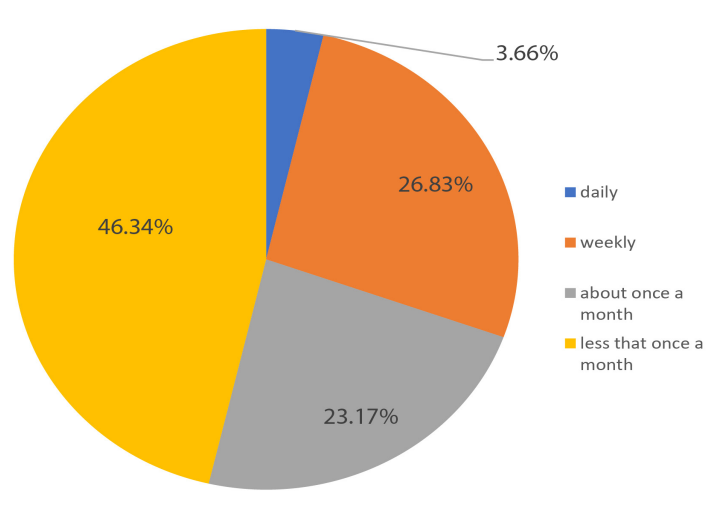

$2009-10(n=82)$

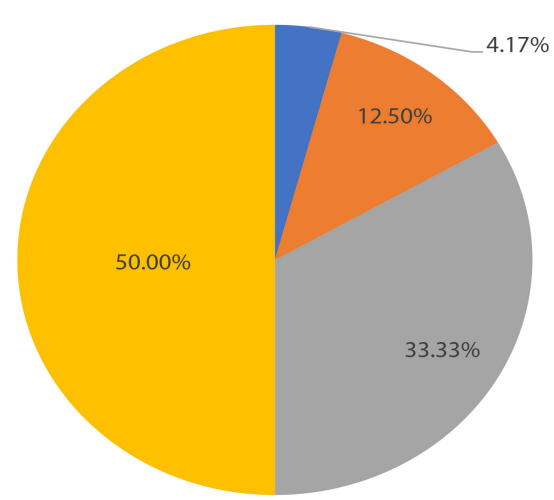

$2016(n=96)$

Fig. (2). How often do you use Wikipedia for medical information?

There is no statistically significant difference between the two sets of data.

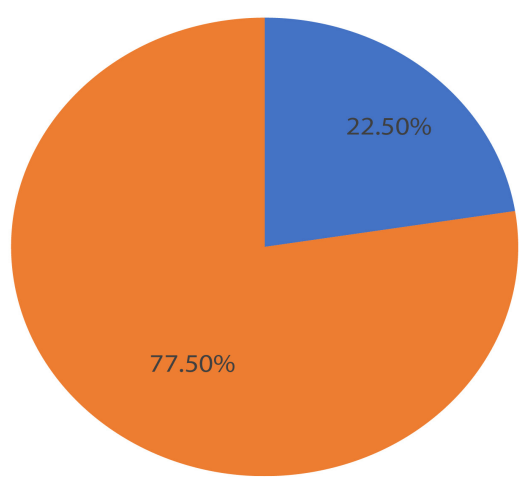

$2009-10(n=80)$

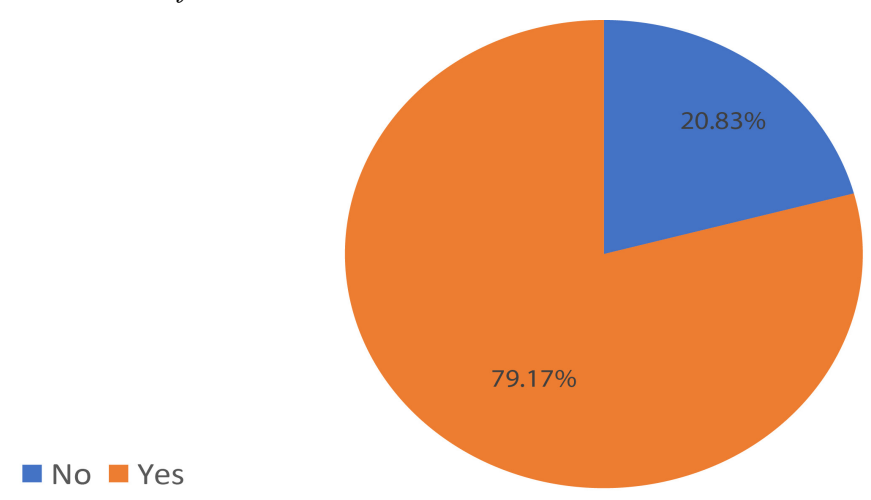

$2016(n=96)$

Fig. (3). Do you routinely check the information on Wikipedia with another source?

There is no statistically significant difference between the two sets of data. 


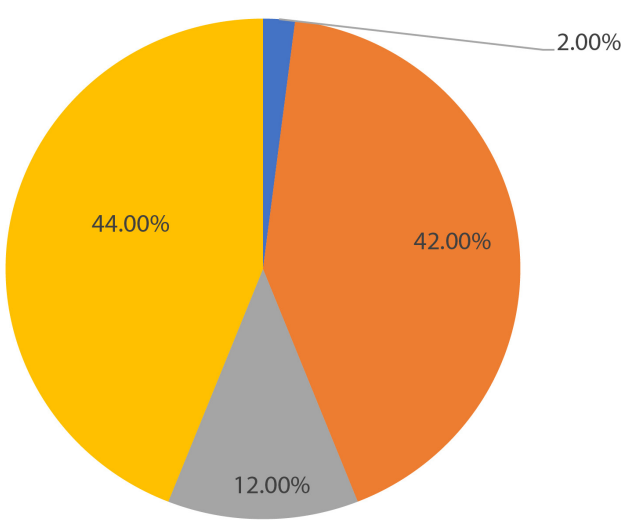

$2009-10(n=100)$

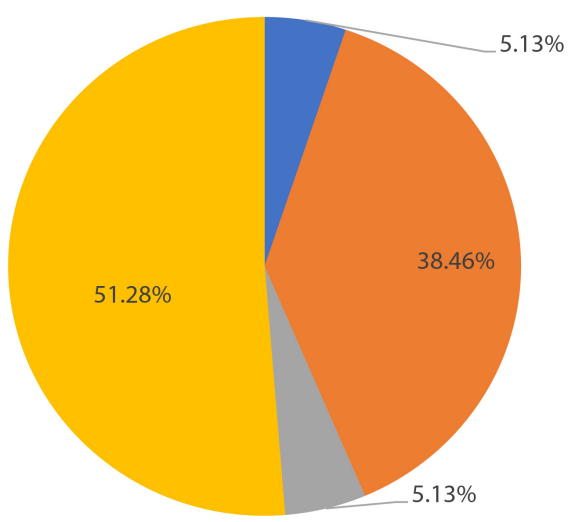

$2016(n=156)$

Fig. (4). How much trust to place in the validity of the information you obtain from Wikipedia?

There is no statistically significant difference between the two sets of data.

\subsection{Why and How to Use Wikipedia as an Aid to Clinical Decision-Making}

Both groups gave very similar reasons in freetext comments for using Wikipedia to aid their clinical decisionmaking and these are in keeping with similar studies as cited above:

- Easily accessible

- Clear concise layout

- Easy to read

- One website to use for almost any piece of information (not assumed to be $100 \%$ accurate).

- Used by so many people that errors likely to be corrected quickly because it can be edited

The criteria used by both groups to judge the reliability and validity of Wikipedia entries were typically:

- Used as starting point rather than endpoint

- Never made clinical decisions based only on Wikipedia

- Always used with/compared to other credible or peer-reviewed sources/cross referenced

- Concordance or otherwise with what the respondent already knows

- Not assumed to be $100 \%$ accurate so always keep a critical approach

- Information generally accurate/high quality

- References to peer-reviewed papers followed up

- Own papers cited on Wikipedia

Notwithstanding the obvious danger of there being confirmation bias, it would seem that our respondents generally applied the same criteria as Wikipedia applies to itself $[17,18,40,50]$. They tend to exhibit caution over Wikipedia entries, exactly as Wikipedia suggests should be the case. As one respondent put it: I would never accept information from a single source. Any suggestion that the peer reviewed literature is free from error... [ellipsis in the original]. They concurred with Rössler et al. that Wikipedia gives a fast overview [63] and, like the students in Herbart et al. [39], used it as a starting point for further reading.

\section{CONCLUSION}

Given the near-ubiquity of Wikipedia as a source of information on just about any topic and its widespread use by medical students and doctors in training, it is difficult to imagine that it will cede its dominant position any time soon. Accuracy and reliability have clearly been of justifiable concern and will, despite efforts to the contrary, likely remain so. The fact that anyone can edit does sometimes mean that persons who do not know better do edit. Not all errors and inaccuracies in Wikipedia are born out of malice (as was the case with Hari as mentioned above [11]) but rather out of ignorance of developments - hence the Cochrane/Wikipedia Initiative, created to make as sure as one can be that the sources used are as up to date as possible [51]. 
And yet, perhaps the very doubt over Wikipedia's accuracy is its greatest strength as a means of informal education of doctors. Doubt demands reassurance; reassurance is found by triangulation, by checking with other sources. We are supposed to be in an era of evidence-based medicine [30,31], therefore the development of the skill of triangulation is to be encouraged. It does not take much time to identify articles in peer-reviewed journals which should be never have made it past the reviewers (such as Wakefield et al. in 1998 [41]) or whose publication may once upon a time have been justified but whose content is now out of date. That medical and health articles on Wikipedia can be so fully referenced and still be doubted is arguably a good thing and one whose effects may be spread into other, more trusted, publications. In this way, one might envisage a future in which no one source is taken to be automatically true but in which triangulation and the evaluation of evidence become the norm to the point of banality.

For doctors and other healthcare professionals to embrace editing Wikipedia articles requires them to develop and exercise the skills not just of commununicating scientific ideas in writing, with due regard to the conventions of academic referencing, but also with due regard to the lay audience at whom Wikipedia is aimed. As some of those who have attempted this make clear, such writing is not an easy task but it is one which demands a high level of rigour and clarity of expression $[8,53]$.

\section{ETHICS APPROVAL AND CONSENT TO PARTICIPATE}

Not applicable.

\section{HUMAN AND ANIMAL RIGHTS}

No Animals/Humans were used for studies that are base of this research.

\section{CONSENT FOR PUBLICATION}

Not applicable.

\section{CONFLICT OF INTEREST}

The authors declare no conflict of interest, financial or otherwise.

\section{ACKNOWLEDGEMENTS}

Declared none.

\section{REFERENCES}

[1] Home of the first website Accessed: 11 December 2016 2016. Available at: http://info.cern.ch/

[2] Total Number of Websites 2016. Available at: http://www.internetlivestats.com/total-number-of-websites/

[3] Egan M. What is the Dark Web? How to access the Dark Web What's the difference between the Dark Web and the Deep Web? 2016. Available at: http://www.pcadvisor.co.uk/how-to/internet/what-is-dark-web-how-access-dark-web-deep-joc-beautfiulpeople-3593569/

[4] Greenhow C, Robelia B, Hughes J. Web 2.0 and Classroom Research: What Path Should We Take Now? Educ Res 2009; $38(4): 246-59$. [http://dx.doi.org/10.3102/0013189X09336671]

[5] Naughton J. A brief history of the future: origins of the internet. London: Phoenix 2000.

[6] George DR, Rovniak LS, Kraschnewski JL. Dangers and opportunities for social media in medicine. Clin Obstet Gynecol 2013; 56(3): 453-62. [http://dx.doi.org/10.1097/GRF.0b013e318297dc38] [PMID: 23903375]

[7] Laurent MR, Vickers TJ. Seeking health information online: does Wikipedia matter? J Am Med Inform Assoc 2009; 16(4): 471-9. [http://dx.doi.org/10.1197/jamia.M3059] [PMID: 19390105]

[8] Azzam A, Bresler D, Leon A, et al. Why medical schools should embrace wikipedia: Final-year medical student contributions to wikipedia articles for academic credit at one school. academic Medicine Journal of the Association of American Medical Colleges 2016.

[9] Brioschi F. Wikipedia: una rivoluzione silenziosa che sta cambiando la realtà. In: Laszlo E, Biava P, Eds. Il senso ritrovato. Rome: SpringerVerlag 2013. [http://dx.doi.org/10.1007/978-88-470-2832-6_9]

[10] O'Reilly T. What Is Web 2.0. Design patterns and business models for the next generation of software communications \& strategies 2007; 65: 17-37.

[11] Aikenhead D. Johann Hari: I failed badly. When you harm people, you should shut up, go away and reflect on what happened. The Guardian. 2015 . 
[12] Metcalfe D, Powell J. Should doctors spurn Wikipedia? J R Soc Med 2011; 104(12): 488-9. [http://dx.doi.org/10.1258/jrsm.2011.110227] [PMID: 22179287]

[13] Encyclopédie 2017. Available at: https://en.wikipedia.org/wiki/Encyclopédie

[14] Henk E. Academics and Wikipedia: Reframing Web 2.0 as a disruptor of traditional academic power knowledge arrangements. Campus-Wide Inf Syst 2010; 27(3): 173-85. [http://dx.doi.org/10.1108/10650741011054474]

[15] Knight C, Pryke S. Wikipedia and the University, a case study. Teach High Educ 2012; 17(6): 649-59. [http://dx.doi.org/10.1080/13562517.2012.666734]

[16] Burgos C, Bot A, Ring D. Evaluating the effectiveness of a wiki internet site for medical topics. J Hand Microsurg 2012; 4(1): 21-4. [http://dx.doi.org/10.1007/s12593-012-0064-0] [PMID: 23730084]

[17] Wikipedia: Identifying reliable sources (medicine) https://en.wikipedia.org/wiki/Wikipedia:Identifying_reliable_sources_(medicine)

[18] Wikipedia:Verifiability 2016. Available at: https://en.wikipedia.org/wiki/Wikipedia:Verifiability

[19] Dunne SS, Cummins NM, Hannigan A, Shannon B, Dunne C, Cullen W. Generic medicines: an evaluation of the accuracy and accessibility of information available on the Internet. BMC Med Inform Decis Mak 2013; 13: 115 [http://dx.doi.org/10.1186/1472-6947-13-115] [PMID: 24099099]

[20] Konieczny P. Teaching with Wikipedia in a 21st-century classroom: Perceptions of Wikipedia and its educational benefits. J Assoc Inf Sci Technol 2016; 67(7): 1523-34.

[http://dx.doi.org/10.1002/asi.23616]

[21] Soules A. Faculty perception of Wikipedia in the California State University System. New Libr World 2015; $116(3 / 4): 213-26$. [http://dx.doi.org/10.1108/NLW-08-2014-0096]

[22] Frey EF. The earliest medical texts. Clio Med 1985-1986; 20(1-4): 79-90. [PMID: 2463895]

[23] Mattern S. Galen and his patients. Lancet 2011; 378(9790): 478-9. [http://dx.doi.org/10.1016/S0140-6736(11)61240-3] [PMID: 21826808]

[24] Markel H. The excruciating final hours of President George Washington 2016. Available at: http://www.pbs.org/newshour/updates/dec-14-1799-excruciating-final-hours-president-george-washington/

[25] Paracelsus . 2016. Available at: https://en.wikipedia.org/wiki/Paracelsus

[26] Matheson D. Post-compulsory education in Suisse romande. Glasgow: University of Glasgow 1992.

[27] Matheson DJ. An examination of some of the difficulties of establishing an open university in a small linguistic area: the case of Suisse romande. Int J Lifelong Educ 1996; 15(2): 114-24. [http://dx.doi.org/10.1080/0260137960150206]

[28] Matheson C, Matheson D. Access and Accessibility in E-Learning. In: Donnelly R, McSweeney F, Eds. Applied E-Learning and E-Teaching in Higher Education. Hershey, PA: IGI Global 2009. [http://dx.doi.org/10.4018/978-1-59904-814-7.ch007]

[29] Freire P. A Pedagogy of the Oppressed. Harmondsworth: Penguin 1996.

[30] Sackett DL, Rosenberg WM, Gray JA, Haynes RB, Richardson WS. Evidence based medicine: what it is and what it isn't. BMJ 1996; 312(7023): 71-2. [http://dx.doi.org/10.1136/bmj.312.7023.71] [PMID: 8555924]

[31] Greenhalgh T. Narrative based medicine: narrative based medicine in an evidence based world. BMJ 1999; 318(7179): 323-5. [http://dx.doi.org/10.1136/bmj.318.7179.323] [PMID: 9924065]

[32] Osler W. 2015. Available at: https://en.wikiquote.org/wiki/William_Osler

[33] Ozdoba C. Wikipedia: A good address for neuroradiologists? Clin Neuroradiol 2011; 21(3): 181-2. [http://dx.doi.org/10.1007/s00062-011-0098-x] [PMID: 21853303]

[34] Hasty R, Garbalosa R. Wikipedia vs peer-reviewed medical literature for information about the 10 most costly medical conditions. J AM Ost Assoc 2013; 114(5): 368-73.

[35] Chatterjee A, Cooke R, Furst I, Heilman J. Is Wikipedia's medical content really 90\% wrong? [Internet]: Official Blog of the Cochrane Community 23 June $2014 \quad$ [cited 13 December 2016 at: http://community-archive.cochrane.org/news/blog/wikipedia $\%$ E2\%80\%99s-medical-content-really-90-wrong

[36] Health information on Wikipedia 2016. Available at: https://en.wikipedia.org/wiki/Health information on Wikipedia. Accessed: 13 December 2016

[37] Heilman MJ, West GA. Wikipedia and Medicine: Quantifying Readership, Editors, and the Significance of Natural Language. J Med Internet Res 2015; 17(3): e62. 
[38] Haigh CA. Wikipedia as an evidence source for nursing and healthcare students. Nurse Educ Today 2011; 31(2): 135-9. [http://dx.doi.org/10.1016/j.nedt.2010.05.004] [PMID: 20646799]

[39] Herbert V. Andreas Frings, Rehatschek H, Richard G, Leithner A. Wikipedia - challenges and new horizons in enhancing medical education. BMC Med Educ 2015; 15(32)

[40] Heilman JM, Kemmann E, Bonert M, et al. Wikipedia: a key tool for global public health promotion. J Med Internet Res 2011; 13(1): e14. [http://dx.doi.org/10.2196/jmir.1589] [PMID: 21282098]

[41] Wakefield AJ, Murch SH, Anthony A, et al. Ileal-lymphoid-nodular hyperplasia, non-specific colitis, and pervasive developmental disorder in children. Lancet 1998; 351(9103): 637-41. [http://dx.doi.org/10.1016/S0140-6736(97)11096-0] [PMID: 9500320]

[42] Deer B. Secrets of the MMR scare. The Lancet's two days to bury bad news. BMJ 2011; 342: c7001. [http://dx.doi.org/10.1136/bmj.c7001] [PMID: 21245118]

[43] Deer B. Secrets of the MMR scare. How the vaccine crisis was meant to make money. BMJ 2011; 342: c5258. [http://dx.doi.org/10.1136/bmj.c5258] [PMID: 21224310]

[44] Deer B. How the case against the MMR vaccine was fixed. BMJ 2011; 342: c5347. [http://dx.doi.org/10.1136/bmj.c5347] [PMID: 21209059]

[45] Hughes B, Joshi I, Lemonde H, Wareham J. Junior physician's use of Web 2.0 for information seeking and medical education: a qualitative study. Int J Med Inform 2009; 78(10): 645-55. [http://dx.doi.org/10.1016/j.ijmedinf.2009.04.008] [PMID: 19501017]

[46] Jacqueline Laika's MedLibLog [Internet] https://laikaspoetnik.wordpress.com/2013/07/12/medpedia-the-medical-wikipedia-is-dead-and-we-missed-its-funeral/. 2013. [15 Nov 2016]. Available at: https:/laikaspoetnik.wordpress.com/2013/07/12/medpedia-the-medical-wikipedia-is-dead-and-we-missed-its-funeral/.

[47] Ganfyd main page 2017. Available at: http://www.ganfyd.org/index.php?title=Main_Page. Accessed: 3 January 2017

[48] Non-alcoholic fatty liver disease 2016. Available at: http://www.ganfyd.org/index.php?title=Non-alcoholic_fatty_liver_disease

[49] Rasberry L. Wikipedia: what it is and why it matters for healthcare. BMJ 2014; 348(g2478): g2478. [http://dx.doi.org/10.1136/bmj.g2478] [PMID: 24714406]

[50] WikiProject Medicine 2016. Available at: https://en.wikipedia.org/wiki/Wikipedia:WikiProject_Medicine. Accessed: 15 Nov 2016

[51] Cochrane Collaboration-Wikipedia $\quad$ Initiative 2016. https://meta.wikimedia.org/wiki/Cochrane_Collaboration-Wikipedia_Initiative/Welcome. Accessed: 25 November 2016

[52] Cochrane: about us 2016. Available at: http://www.cochrane.org/about-us. Accessed: 26 November 2016

[53] Health CO. Editorial base blog Rewriting Wikipedia 2016. Available at: https://cochraneohg.wordpress.com/2016/07/08/rewriting-wikipedia/. Accessed: 26 November 2016

[54] Get started with shared decision-making 2017. Available at: http://sdm.rightcare.nhs.uk/. Accessed: 4 January 2017

[55] Natarajan A, Racherla S. Wikipedia: encyclopaedia cardiologica. J R Soc Med 2012; 105(5): 191. [http://dx.doi.org/10.1258/jrsm.2012.120012] [PMID: 22637767]

[56] Masukume G, Kipersztok L, Das D, Shafee TM, Laurent MR, Heilman JM. Medical journals and Wikipedia: a global health matter. Lancet Glob Health 2016; 4(11): e791.

[http://dx.doi.org/10.1016/S2214-109X(16)30254-6] [PMID: 27765289]

[57] Wikipedia talk: WikiProject Medicine 2017. Available at: https://en.wikipedia.org/wiki/Wikipedia_talk:WikiProject_Medicine. Accessed: 7 April 2017

[58] Wikipedia:Wikipedia program education in at: https://en.wikipedia.org/wiki/Wikipedia:Wikipedia_education_program_in_medicine. Accessed: 7 April 2017

[59] WikiProject CRUK 2016. Available at: https://en.wikipedia.org/wiki/Wikipedia:WikiProject_CRUK. Accessed: 7 April 2017

[60] Matheson D, Matheson C, Campain N, Price T, Collins P. The use of Wikipedia in clinical decision-making Association for Medical Education in Europe 2011. 29-31 August. Vienna

[61] Poulter M. Doctors use, but don't rely totally on, Wikipedia 2017. https://blog.wikimedia.org.uk/2012/04/doctors-use-but-dont-rely-totally-on-wikipedia/. Accessed: 11 January 2017

[62] Matheson D, Matheson C. Medical and healthcare practitioners' use of Wikipedia in clinical decision-making. Biannual Conference of the Comparative Education Society in Europe. 30 May - 3 June 2016; Glasgow.

[63] Rössler B, Holldack H, Schebesta K. Influence of wikipedia and other web resources on acute and critical care decisions a web-based survey ESICM LIVES 2015; 3-7 October Berlin. 2015.

(C) 2017 Matheson and Matheson-Monnet.

This is an open access article distributed under the terms of the Creative Commons Attribution 4.0 International Public License (CC-BY 4.0), a copy of which is available at: https://creativecommons.org/licenses/by/4.0/legalcode. This license permits unrestricted use, distribution, and reproduction in any medium, provided the original author and source are credited. 